\title{
А.В.ЛОГУТОВ \\ ЗВУКОВЫЕ ПРАКТИКИ \\ И МАТЕРИАЛЬНОСТЬ \\ ГОРОДСКОГО ПРОСТРАНСТВА
}

Urban Studies and Practices Vol.2 \#4, 2017, 39-50

https://doi.org/10.17323/usp24201739-50

Логутов Андрей Владимирович, кандидат филологических наук, доцент кафедры теории дискурса и коммуникации филологического факультета МГУ имени М.В. Ломоносова, руководитель научного семинара «Антропология звука» (facebook.com/soundstudiesmoscow); Российская Федерация, 119991, Москва, ГСП-1, ул. Ленинские горы, д. 1.

E-mail: logutow@mail.ru

В статье рассматривается звуковое пространство города в контексте различения приватной и публичной сфер. Апеллируя к идеям М. Маклюэна, Р.М. Шейфера, Дж. Мовитта, автор предлагает видеть в аудиальных городских практиках медийные интерфейсы, работающие на стыке публичного и приватного. Эти интерфейсы имеют конкретно-материальную природу, что осложняет их картографирование и теоретическое освоение. Выдвигается гипотеза о том, что обращение к аудиальной модальности позволяет плодотворно описывать некоторые типы взаимодействия между публичным и приватным. В качестве примеров рассматриваются некоторые практики городского слушания.

Ключевые слова: звуковые исследования; антропология; городской звук; приватное; публичное

3 вуковое измерение городской жизни стало предметом научного рассмотрения относительно недавно: применительно к западной научной традиции речь идет о глубине в 60-70 лет, русскоязычные же работы начали появляться только в последнее десятилетие. Впрочем, первые попытки законодательного и административного регулирования городского звука предпринимались значительно раньше. Научная мысль, как это часто бывает, отстает от рефлексируемых в ней предметных изменений, но благодаря значимому усилию, предпринятому в последние годы как в области звуковых исследований, так и в урбанистике, дистанция между ними сокращается.

Развитие крупных индустриальных городов в XIX-XX вв. шло параллельно с развитием новых техник производства, передачи и сохранения информации. На наш взгляд, осмысленный разговор о городской среде невозможен без разговора о медийных практиках в широком смысле слова. В своем тексте «По городу пешком» ${ }^{1}$ М. де Серто описывает два способа смотреть на город: с одной стороны, это взгляд «сверху вниз», с высоты птичьего полета, позволяющий охватить и мыслить городское пространство как единое целое; с другой стороны - это «горизонтальный» взгляд агента, движущегося по улицам и постепенно прочитывающего текст открывающихся перед ним городских пространств. Одна из проблем, стоящих как перед теоретическими, так и перед практически ориентированными исследованиями в урбанистике, состоит в увязывании этих двух масштабов, выявлении механизмов, при помощи которых микро- и макроуровни составляют динамическое единство города. На наш взгляд, эта задача может быть решена в том числе при помощи аппарата медиологии. Медиация, понимаемая

1 Де Серто М. По городу пешком // Социологическое обозрение. 2008. № 2. С. 24-38. Перевод главы из книги «Практика повседневной жизни» (1980). 
в широком смысле как стратегия и технология опосредования, может стать одним из ключевых понятий, проливающих свет на характер связей между городскими практиками «низкого уровня» и эмерджентными феноменами, свойственными городу как целому.

Комплементарное взаимодействие между этими двумя формациями давно стало одним из центральных мотивов городских исследований (прежде всего, социологического толка). Уже в своем эссе «Большие города и духовная жизнь» (1903) [Зиммель, 2002, с. 1-12] один из отцов современной социологии Георг Зиммель задается вопросом о взаимодействии между индивидуальной «духовной жизнью» городских жителей (микроуровень) и устройством города как целого (макроуровень). Это взаимодействие, по Зиммелю, носит преимущественно антагонистический характер: он усматривает основную задачу городского жителя в «охране [своей] субъективной жизни от насилия большого города» [Там же], то есть в беспрестанном отмежевывании своей частной жизненной территории от неприветливого и потенциально враждебного ландшафта общественного. Примечательно, что Зиммель (как потом и В. Беньямин, и М. Маклюэн, и У. Онг) указывает на то, что инструментом подобного отмежевывания оказывается вовсе не активная сосредоточенная экспансия в окружающий мир, а, напротив, равнодушная отстраненность от происходящего вокруг, экранирование внешних раздражителей, замыкание в сфере личного существования. Необходимые отношения с внешней средой подчиняются в таком случае разного рода рациональным протоколам, постоянство которых и обеспечивает солидарное единство городской жизни.

Комментируя идею Зиммеля, обратим внимание на два существенных пункта. Во-первых, упомянутое нами выше разделение микро- и макроуровня городской жизни может быть вслед за немецким социологом - интерпретировано в том числе как различие между частным и общественным (публичным) пространствами. Не вдаваясь глубоко в историю вопроса, напомним, что - как минимум со времен Хабермаса - соотношение между частным и публичным воспринимается как важнейший конститутивный элемент европейского культурного ландшафта ${ }^{2}$. В дальнейшим мы будем употреблять пары «микро- / макроуровень» и «частное / публичное» как синонимичные. Второе замечание состоит в том, что для Зиммеля граница, разделяющая частное и общественное, имеет абсолютную ценность. Разрешение исходного антагонизма между крупно- и мелкомасштабными структурами и практиками (то есть между личным и публичным) возможно только в режиме динамического компромисса, при котором граница между ними может смещаться или даже истончаться, но никогда не исчезает полностью.

В данной статье мы хотели бы попытаться переосмыслить функционирование этой границы, отказавшись от представления о ней как о защитном рубеже, в той или иной степени обеспечивающем автономию частного пространства индивида, и предложив альтернативное понимание ее как механизма медиации между личной и общественной сферами, одним из продуктов которого оказывается переживание материальности городской среды.

\section{Граница как визуальный образ}

Выбранный нами медийный подход очевидным образом требует повышенного внимания к тому, какие каналы, техники и технологии используются воспринимающими агентами для получения информации о городской среде и ориентирования в ней. Вслед за М. Маклюэном мы хотели бы сосредоточиться, прежде всего, на соотношении визуального и аудиального каналов восприятия. По мысли Маклюэна, которую он воспроизвел в ряде работ, современная «электронная» эпоха развития западной цивилизации знаменуется возвращением слуха в процессы культурного строительства, что существенным образом отличает ее от предыдущей, «печатной», эпохи, для которой было характерно абсолютное доминирование зрения³. Заметим, что терминологический ряд, связанный с соотношением приватного и публичного, крупно- и маломасштабных структур, приведенный нами в предыдущем разделе, имеет сугубо визуальный характер. Такие слова, как «сфера», «пространство» и «граница», - это зрительные метафоры, неявно переводящие любой порождаемый ими дискурс на «визуальные рельсы». Это касается в равной мере и научно-теоретического разговора о городах, и «прак-

2 Прежде всего имеется в виду работа [Habermas, 1991].

3 Прежде всего имеется в виду работа [Маклюэн, 2005]. 
тической урбанистики» - архитектуры, городского планирования и смежных дисциплин. Использование визуального языка располагает, с одной стороны, к аналитическому разъятию (óvód $v \sigma ı \varsigma$ - разложение) города на более или менее автономные компоненты, которые могут быть комбинаторно соположены друг с другом в режиме коллажа. Это, в свою очередь, приводит к иллюзии возможности исчерпывающего картографирования городского пространства. С другой стороны, визуальность языка если не полностью исключает, то существенно затрудняет рассмотрение образа города в иных модальностях (звуковой, обонятельной, тактильной, проприоцептивной).

Хорошей иллюстрацией этому служат многочисленные попытки картографирования городского саундскейпа, из которых мы хотели бы выделить исследования Саутверта, Шейфера и недавнюю коллективную публикацию Корнфелда, Шивеи, Дайкса [Southworth, 1969, p. 49-70; Schafer, 1977; Kornfeld, Schiewe, Dykes, 2011]. Достаточно самого беглого взгляда на эти работы, чтобы прийти к выводу о том, что системы визуализации звука неизбежно неполны и несут на себе отпечаток авторского произвола. Так, в приложении к книге Шейфера мы находим две карты [Schafer, 1977, p. 264-265], построенные по принципиально различным принципам, каждый из которых представляется ad hoc разумным и обоснованным применительно к поставленной задаче, но между которыми сложно найти точки соприкосновения. Система, предложенная в работе Корнфелда, Шиве и Дайкса, более последовательна и, по нашему мнению, может с успехом претендовать на статус стандарта визуализации городского звука. Однако сами авторы с присущей им академической осмотрительностью предупреждают читателя о том, что:

Визуализация звука возвращает нас к фундаментальной проблеме визуализации данных, не имеющих отношения к привычным формам физической геометрии. <..> Звук - это слышимая и невидимая сущность, не связанная в человеческом восприятии с визуальностью [Kornfeld, Schiewe, Dykes, 2011].

Визуализация звука (envisioning sound) проблематична в силу того, что она не входит в круг знакомых широкой публике практик репрезентации и поэтому не может быть легко прочита$\mathrm{Ha}^{4}$. Сильной стороной визуализации является то, что она позволяет представить акустические данные в «однозначном и хорошо различимом» ${ }^{5}$ виде, то есть объективно. На это указывает и Шейфер в комментарии к первой из вышеупомянутых карт. Трудность, однако, заключается в том, что визуализацию сложно соотнести с наполнением реального слушательского опыта городского жителя, то есть независимо от масштаба карты она всегда оперирует на макроуровне и не может заполнить зазор между конкретным аудиальным переживанием места и его обобщенными структурными свойствами. Существенный вклад в сложность этой задачи вносит общий родовой недостаток карт как таковых, нашедший выражение в афоризме А. Коржибски «Карта не есть территория» и рассказе Борхеса «О строгой науке»:

...Искусство Картографии достигло у них в Империи такого совершенства, что Карта одной-единственной Провинции занимала целый Город, а карта Империи - целую Провинцию. Со временем эти Несоразмерные Карты нашли неудовлетворительными, и Коллегия Картографов создала Карту Империи, которая была форматом в Империю и совпадала с ней до единой точки [Борхес, 2017, с. 567].

Неизбежная обобщенность любой карты вкупе с проблематичностью визуализации звуковых событий заставляет нас искать иные способы сближения между микро- и макроуровнями ${ }^{6}$. В зрительной модальности городское пространство относительно легко картографируется, подменяясь более или менее статичной моделью («картой»), из которой уже в силу самой

4 Заметим, что это касается почти всех систем визуализации звука: от спектрограмм и осциллограмм до нотной записи. Единственной общераспространенной и общепонятной системой такого рода остается алфавитное письмо.

5 "Unique and discernible" [Kornfeld, Schiewe, Dykes, 2011, p. 18].

6 Заметим, что после появления новых медийных способов представления информации задача адекватной репрезентации звуковой реальности города становится намного более выполнимой. Речь идет, например, о таких проектах, как Record the Earth Университета Пердью, в которых аудиофрагменты связываются 
ее абстрактности изымается пласт индивидуального и коллективного опыта взаимодействия с городом как материальной средой. Это заметно в том числе в практиках городского проектирования, в которых предпочтение отдается схематической организованности визуального пространства, а не созданию среды, способной производить новые контактно-телесные впечатления в слуховой, осязательной, проприоцептивной и обонятельных модальностях. Представляется, что в таких условиях страдает и сама визуальность: изъятое из целостности сенсориума и оторванное от повседневных практик восприятия зрение сводится к умозрению, а пространство - к карте. Этот процесс родственен тому, что, по мнению М. Маклюэна, происходит с культурно-информационными процессами в эпоху книгопечатания: на место живой, действующей речи приходит абстрактный, существующий вне своего конкретно-материального воплощения текст, а на место коллективных практик чтения вслух - беззвучное индивидуальное чтение «про себя».

Примечательно, что как звуковая экология (Р.М. Шейфер, Б. Кроз и др.), так и городской звуковой дизайн - в русле маклюэновского возврата к речевой коммуникации в эпоху «вторичной устности» - настойчиво обращаются именно к контактно-телесной роли звука в организации пространства (в том числе и городского). Одно из основных направлений звукового дизайна в городе - это как раз создание сравнительно приватных пространств комфорта (например, Пейли Парк в Нью-Йорке), частично «выключенных» из внешнего саундскейпа. Внимательность к качеству звуковой среды приводит к переосмыслению работы с другими модальностями (визуальной, тактильной, обонятельной) в русле приоритета контактно-телесных переживаний.

Тезис о подлежащем преодолению доминировании визуальности касается в числе прочего и представления о границе, речь о котором шла выше. Если мы понимаем и принимаем границу в визуальных терминах как разделительный рубеж, проходящий (в нашем случае) между пространством частного и публичного, то и наша аналитика неизбежно оказывается по одну сторону от нее, в публичной сфере, а сфера частного выскальзывает из нашего поля зрения. В рамках задекларированного нами медийного подхода к проблеме мы хотели бы обратиться к аудиальной модальности как потенциальному источнику искомых решений.

\section{Особенности слуха как первичного медиума}

В своей книге “Sounds: The ambient humanities” [Mowitt, 2015]7 британский исследователь Джон Мовитт пишет, что «звуковые исследования могут освежить то, как мы осмысливаем выражение социальных практик и сопутствующие им социально-исторические контексты; [важно] не то, какое место мы закрепляем за звуками, а то, как звуки определяют саму процедуру закрепления мест» [Ibid., p. 13]. Звук, таким образом, может претендовать на роль инструмента выявления универсальных социокультурных структур и быть не только предметом научного анализа, но и источником методологических установок и концептуальных построений. В силу ограниченности объема данной статьи и недостаточной, на наш взгляд, обоснованности некоторых конъюнктур, представленных Мовиттом, мы воздержимся от применения предлагаемого британским исследователем понятийного аппарата и сосредоточимся на его методологической установке в широком смысле, заключающейся в том, что проблемы, плохо решаемые в визуальной модальности, могут быть существенным образом прояснены при переходе в модальность аудиальную.

Перечисление сущностных различий между зрением и слухом как первичными медиа можно найти в ряде работ по звуковым исследованиям. Здесь мы воздержимся от приведения всего списка ${ }^{8}$ и сосредоточимся на трех свойствах аудиального восприятия, наиболее важных для стоящей перед нами задачи.

Во-первых, благодаря своей всенаправленности слух создает холистическую, целостную картину окружающего мира. Если в зрительной картине мы можем более или менее опреде-

с определенными точками на карте. Впрочем, изменчивость городских звуков налагает ограничения даже на такие подходы.

7 Обзор книги на русском языке см. в работе [Логутов, 2016].

8 Отсылаем читателя к Введению к хрестоматии [The Sound Studies Reader, 2012] за авторством Дж. Стерна, а также к статье [Логутов, 2014]. 
ленно вычленить те или иные объекты, то в звуковом ландшафте звучания часто оказываются неотделимыми друг от друга, особенно если речь идет о средах «низкого разрешения» (lo-fi), которые, по Шейферу, характерны как раз для больших индустриальных городов [Schafer, 1977, $p$. 43]. Холистичность аудиального мира означает де-факто отсутствие объективно существующих, независимых от местоположения и слушательских привычек индивида границ между горизонтами разных звуковых событий. Как пишут Карпентер и Маклюэн, «...[а]удиальное пространство не имеет выделенной центральной точки; оно создается самим объектом, а не содержит объект. Оно непохоже на загнанное в рамку изобразительное пространство и пребывает в постоянном динамическом течении, создавая секунда за секундой собственные измерения» [Carpenter, McLuhan, 1960, p. 67].

Будет также неверно утверждать, что звук преодолевает границы, приписывая ему тем самым некие трансгрессивные свойства; точнее, само понятие границы трудно сформулировать на основе звуковых данных, так как - в отличие от реальности визуальной - звуковая реальность складывается не из объектов, а из событий9.

Второй важный момент заключается в теснейшей связи между аудиальным восприятием и аффектом, в том числе - с комфортом или дискомфортом нахождения в том или ином месте. Это свойство в совокупности с упомянутой уже холистичностью определяет существенную роль звука в создании целостного образа городской среды: «Город, воспринимаемый исключительно через зрение, почти полностью отграничен от индивида и разворачивается перед ним в ограниченном наборе визуальных форм. Все за пределами поля зрения становится неизвестным» [Southworth, 1969, p. 51]. В своем классическом опыте по изучению бостонского саундскейпа М. Саутверт использовал три группы испытуемых: члены контрольной группы воспринимали город визуально и аудиально, у членов «аудиальной группы» были завязаны глаза, а в «визуальной группе», наоборот, был заблокирован слуховой канал восприятия. По свидетельству членов «визуальной группы», обеззвученный город произвел на них удручающее впечатление: «...город казался печальным, лишенным всякого контраста местом, почти двумерным. <...> Открытость, бессобытийность, вульгарность, необъятность и монотонность пространства сложились в очень неприятный опыт» [Southworth, 1969, p. 61]. Сходная симптоматика - депрессивные расстройства, тревожность, компульсивное поведение, фобии и пр. - сопровождает потерю слуха у взрослых пациентов ${ }^{10}$. Важность аудиальной информации для эмоционально-аффективного восприятия городского пространства признается также социологами и географами ${ }^{11}$.

B-третьих, слуховое восприятие вносит существенный вклад не только в целостность и эмоциональную насыщенность образа города, но и в ощущение включенности индивида в городскую среду: «Аудио-тактильное пространство - это пространство вовлеченности. Без него мы теряем связь с окружающим. Визуальное пространство - это пространство отстраненности и осторожности, составляющих то, что мы называем научным методом, широким кругозором и эрудицией» [McLuhan, 1970, p. 194]. По остроумному замечанию поэтессы Сьюзен Стюарт (Susan Stewart), слух - это осязание на расстоянии. Действительно, в отличие от света, звук, как и любые другие механические колебания, обладает очевидной для человека материальностью.

Кроме того, звук ассоциативно и перцептивно связан с привычными типами движений объектов и сред, с различными окружающими человека природными и рукотворными процессами (звук ветра и воды, звук трения и т.д.). Звук интерактивен (responsive в терминах Саутверта); как заметил Ж. Деррида в «Голосе и феномене», человек дан себе в слухе в значительно большей мере, чем в зрении [Деррида, 1999, с. 15-136, 98-115]: мы слышим собственный голос, наше тело способно производить целый ряд как произвольных, так и непроизвольных звуков. Степень интерактивности взаимодействия с окружающим нас саундскейпом, конечно, определяется свойствами последнего: именно в этом ключе Саутверт и Шейфер критикуют шумные городские ландшафты «низкого разрешения», авторитарно экранирующие звуки, издаваемые отдельным человеком. Не намереваясь углубляться в суть этой критики, отметим только,

9 Тезис о различии между звуковыми «объектами» и «событиями» до Шейфера разрабатывался Пьером Шаффером и Мишелем Шионом. См. в связи с этим сравнительно позднюю, но исчерпывающую вопрос публикацию [Chion, 1983].

10 См. систематический обзор исследований по теме в работе [Matthews, 2007].

11 См. обзор (р. 53-84) и библиографию в работе [DeFazio, 2011]. 
что тема материального присутствия человека в звуковой среде является одним из существенных мотивов звуковой урбанистики.

\section{Материальность}

Теперь мы готовы приступить к раскрытию термина «материальность», вынесенного в название нашей статьи. Мы предлагаем понимать материальность как эффект, возникающий в точке контакта между индивидом («внутренним» миром) и средой («внешним» миром) в силу динамической неопределенности положения этой точки и природы обеспечиваемого ею контакта. Так как любой контакт такого рода всегда опосредован при помощи первичных или вторичных (технических) медиа, материальность являет собой медийный эффект сродни «эффекту реальности», о котором применительно к литературе писали Р. Якобсон и Р. Барт ${ }^{12}$. Материальность возникает не благодаря только лишь установлению контакта между миром внутри и миром снаружи, а благодаря неопределенности этого контакта, благодаря тому сопротивлению, с которым эти два мира встречают друг друга. Материальность - это эффект «Плотности» среды, ее субстанциального нежелания перестать быть собой и одновременно ее неспособности подчинить себе все остальное. Сходное толкование этого термина мы находим, например, в работе Лейтема и МакКормика: «М хотели бы присоединиться к исследователям, определяющим материальность как актуальное, конкретное и реальное, то есть обладающее известной твердостью - в противоположность нематериальному, абстрактному и нереальному» [Latham, McCormack, 2004, p. 704]. Материальность в таком понимании - это эмерджентный феномен, эффект, рождающийся из взаимодействия множества мобильных субъектов со средой, порождаемой этим взаимодействием ${ }^{13}$.

Эффект материальности имеет отношение к переживанию неподручности окружающего мира, его относительной автономии от индивида, и одновременно - постоянной нечеткости границ этой автономии. В этом смысле то сопротивление, которое аудиальная городская среда оказывает визуальному картографированию, есть проявление ее материальности ${ }^{\mathbf{1 4}}$.

Разумеется, всякий более или менее нетривиальный материал будет оказывать сопротивление всякой объяснительной модели в силу неизбежной ограниченности последней. Мы далеки от мысли о том, что аудиально ориентированная аналитика будет способна решить все проблемы городских исследований и создать идеально точное, непротиворечивое и избавленное от лакун представление о городе. Кажется реалистичным, однако, что в силу характерных свойств аудиальной модальности, перечисленных в предыдущем разделе, исследователю выгодно обращаться к звуковому восприятию и звуковым практикам в тех случаях, когда речь идет об описании динамических, пограничных, «нечетких» процессов, которые плохо поддаются визуальному эксплицированию.

Наше определение материальности влечет за собой еще одно важное следствие: материальность возрастает в ситуации неопределенности границ между взаимодействующими областями. Чем больше «пятно» контакта между ними, чем более подвижны его границы, чем больше «пропускная способность» этих границ, тем больше окажется степень вовлечения индивида в соответствующие медийные практики, потому что именно в них он сможет в наибольшей степени рискнуть своей автономией и одновременно утвердиться в ней. Здесь нам снова хотелось бы сделать отсылку к теории художественного реализма Барта и Якобсона ${ }^{15}$, которые указывали на важность избыточности для создания реалистического эффекта. Перенасыщен-

12 Напомним, что и Барт, и Якобсон рассматривали «реализм» как эмерджентное свойство литературного текста, как эффект, возникающий на стыке между письмом и чтением, то есть определяющийся как свойствами укорененного в литературной традиции текста, так и читательскими ожиданиями и стратегиями, свойственными конкретной культурно-исторической формации. См.: [Барт, 1994, с. 392-400; Якобсон, 1987, c. 387-393].

13 См. также сходные размышления в работах [Johnson, 2001; Clark, 2000, p. 12-33; Massumi, 2002].

14 Это понимание, разумеется, слишком широко и выходит далеко за пределы предмета настоящей статьи. Однако нам важно подчеркнуть, что понятие материальности работает и на метауровне, позволяя уподобить взаимодействие между индивидом и городом как средой обитания обращению ученого-урбаниста с городом как научной проблемой.

15 В строгом смысле слова никакой совместной «теории реализма Барта - Якобсона», разумеется, не существует. Мы позволили себе вольность объединить их подходы в одном рассуждении только в силу того, что интересующий нас тезис присутствует в обеих концепциях. 
ность «реалистического» текста деталями, не нагруженными никаким однозначным, подлежащим восстановлению «смыслом», как раз и ответственна за характерный «эффект реализма». Похожую мысль мы встречаем у Вальтера Беньямина применительно к фотографии: именно избыточность фотографического изображения придает ему известную документальность.

Предлагаемая нами на суд читателя концепция аудиальной материальности вряд ли поможет нам уточнить определение того, что такое приватное и публичное пространства, взятые в отдельности друг от друга, просто потому, что в звуковых городских практиках их отдельность как раз сравнительно редка ${ }^{16}$ : «Звучные колебания аудиальной материальности расшатывают границы между приватным и публичным» [Labelle, 2010]. Мы надеемся не прояснить статус этих сфер как независимых феноменов в логике веберовских идеальных типов, а продемонстрировать продуктивность рассмотрения практик, в которых границы между ними становятся предельно нечеткими.

Технологии XIX-XX вв. существенным образом изменили палитру видов деятельности и значений, привязанных к «дому» как архетипически личному локусу. Захватывая все новые пространства, медиа начали транслировать публичный контент в (некогда) приватные области и наоборот. В следующих разделах мы конспективно рассмотрим два примера звуковых технологий (автомобильный радиоприемник и портативный плеер), которые, на наш взгляд, удачно иллюстрируют размышления о продуктивности концепции аудиальной материальности городской среды ${ }^{17}$.

\section{Автомобильное радио}

Автомобиль - это, пожалуй, идеальный пример совмещения идей приватности и мобильности. В современных постиндустриальных условиях, когда социальное пространство воспринимается не столько как совокупность различных локусов со свойственными для них практиками и сценариями, сколько как эмерджентный феномен, порожденный сетевыми связями между людьми, материальность автомобиля начинает казаться слишком тяжеловесной, демонстративной и несколько архаичной. Как пишет - впрочем, не без доли иронии Дж. Джекобс в своей известной книге «Смерть и жизнь больших американских городов», «...[т]ранспортные артерии, парковочные площадки, бензозаправочные станции, магазины и банки для автомобилистов - все это мощные и неутомимые инструменты разрушения городов» [Джекобс, 2011, с. 348]. Отказ от автомобилей, развитие общественного транспорта, велосипедной и пешеходной инфраструктуры находятся в фарватере нынешних урбанистических течений.

С автомобилем связан ряд звуковых практик, каждая из которых заслуживает отдельного разговора; мы же хотели бы кратко остановиться только на одной из них, а именно на прослушивании радио в машине, которое представляется нам тем более интересным, что в эпоху Интернета эфирное радио также воспринимается как определенного рода архаизм. Связь между машиной и радио выражается также в том, что самую большую долю среди современных радиослушателей составляют водители ${ }^{18}$. Вместе с тем в своей тяжеловесности и медлительности автомобиль противоположен радио: для его движения нужны специально оборудованные пространства, которые изменяют лицо города; радио же - эфирный медиум, область распространения которого не имеет четких границ. Автомобильный приемник функционирует как ловушка, материализующая бесплотный публичный радиоэфир, захватывающая произведенный в результате этой материализации звук в приватном пространстве салона и отдающая вовне шум двигателя, который, в свою очередь, и составляет основную - поглощающую все и вся - ноту lo-fi саундскейпа индустриального города. Автомобиль с включенным радио это аудиальный интерфейс, в котором из материала публичного радиоэфира производится

16 Несомненно, существуют и существовали звуковые практики, носящие подчеркнуто публичный или частный характер (например, объявления в транспорте или домашнее музицирование соответственно). Однако в рамках нашего понимания материальности анализ этих практик будет, как представляется, менее продуктивным в плане раскрытия динамического единства приватного и публичного в городском сообществе.

17 Заметим сразу, что мы воздержимся от обсуждения вопроса о порядке взаимовлияния технологического прогресса и социальных изменений: было ли появление новых технологий вызвано возникновением соответствующего запроса в обществе (точка зрения Р. Уильямса) или наоборот (точка зрения М. Маклюэна)?

18 По данным исследования Ю. Николаевой [Николаева, 2015], в 2014 г. доля радиослушателей в России, слушавших радио за рулем, составляла $33 \%$. 
приватность локального приватного пространства (того, что Р.М. Шейфер называет “private bubbles”), а из отходов производства - в силу того, что работа двигателя тратится в том числе на питание радиоприемника, - создается публичный саундскейп улицы, похожий по своим акустическим характеристикам на шум между станциями.

В условиях устойчивого приема сигнала находящееся под постоянным визуальным контролем со стороны водителя передвижение по городу никак не коррелирует с музыкальными и речевыми ритмами, задаваемыми радио. Таким образом, в пределах данного интерфейса приватное пространство организовано визуально, а приватное время - аудиально. При этом - так как радиоэфир одинаков для всех, кто слушает в данный момент данную радиостанцию, - время лишь кажется приватным: часы водителей синхронизированы, чего нельзя сказать про их пространственные траектории, рассогласование между которыми проявляется в неравномерности дорожного движения и то и дело возникающих заторах. Тезис Зиммеля о том, что согласованность городской жизни становится возможной благодаря наличию общего для всех времени ${ }^{19}$, получает в данном случае материальное звуковое воплощение ${ }^{20}$.

В своей книге “Turtles, termites, and trafficjams” [Resnick, 1994] Митчел Резник, анализируя вычислительные модели множественных систем с сихронизированным поведением, предлагает термин «массово параллельные микромиры», который, на наш взгляд, мог бы быть успешно использован для описания подобного рода медийных интерфейсов и который способен уточнить и расширить идею private bubbles Шейфера. К сожалению, нам не удалось найти работ по влиянию прослушивания радио на психологическое восприятие автомобильных заторов в городе или примеров дизайнерских звуковых решений, которые могли бы, например, облегчить связанный с этим стресс в случае пассажиров общественного транспорта.

\section{Портативный плеер}

Портативный плеер Sony Walkman, выпущенный на рынок весной 1980 г., произвел революцию в культуре музыкального потребления. Впрочем, революционность этого изобретения не стоит переоценивать; во многом оно стало реинкарнацией уже известных к тому моменту техник индивидуального потребления звуковой продукции, начиная от уже упомянутого нами автомобильного радио и кончая переносными транзисторными приемниками. Если в случае машин степень автономности приватного звукового пространства была величиной относительной, определявшейся в том числе уровнем внешнего шума и качеством звукоизоляции салона, то после изобретения компанией Etymotyc первых шумоподавляющих наушников-вкладышей в 1991 г. $^{21}$ создание своего собственного аудиального «пузыря» (private bubble) стало доступно рядовому потребителю.

Пожалуй, самым вдумчивым текстом, посвященным культурным и медийным импликациям появления портативного плеера, остается эссе С. Хосокавы “The Walkman effect” ([Hosokawa, 1984, p. 165-180], здесь цит. по [Hosokawa, 2012, p. 167-183]). Изобретение Sony Walkman, по мысли автора, есть симптом нарастающей парцилляции общества, превращения его в сообщество «маленьких мобильных единиц» (здесь Хосокава пользуется выражением Р. Фриппа). При этом парцилляция, распадение на части не воспринимается автором как нечто однозначно негативное. Скорее наоборот: портативный плеер символизирует собой стирание границ между «паразитическим» и «симбиотическим» модусами существования. Мечта о всеобщей симбиотической солидарности и проклятие паразитизма, преследующее общество потребления, каждый член которого нацелен на получение личной выгоды за счет других, сливаются здесь в одном сложном слушающем субъекте. Слушание превращается не только в форму сугубо персонализированной рефлексии («я понимаю себя через то, что слушаю»), но и в форму осу-

19 «Если бы все часы в Берлине внезапно стали неверно или разно показывать время, хотя бы в продолжение одного часа, то вся хозяйственная и прочая жизнь этого города была бы надолго расстроена» [Зиммель, 2002, c. 4].

20 Тезис о том, что синхронизация часов (не только материальных, но и внутренних, в смысле бергсоновской «длительности») у водителей связана с тем, что они слушают радио за рулем, не покажется столь уж неожиданным, если обратить внимание на то, как часто в радиоэфире объявляют текущее время. Кроме того, как пишет Р.М. Шейфер в цитированной нами ранее монографии, ключевую роль в обеспечении общности хода времени в европейских городах, начиная со Средневековья, играла аудиальная практика боя башенных часов или колокольного звона [Schafer, 1977, p. 55-56].

21 Информация с сайта компании etymotic.com/about-us 
ществления идеи «общественного театра», в котором каждый человек играет скоординированную с другими роль.

Хосокаву завораживает визуализированная материальность плеера: человек теперь волен не только слушать, что ему вздумается и где ему вздумается, но и предъявлять себя другим как слушателя. Именно здесь и возникает игра между приватным и публичным, между «владельцами» (теми, у кого есть плеер, - holders) и «наблюдателями» (beholders). Эту игру Хосокава пытается описать через логику «тайны» (secret), одновременно объединяющей и разобщающей: все слушают, но все слушают разное. Форма новой медийной практики объединяет, а ее содержание - разобщает. Это мистическое действо происходит в пространстве города, которое само по себе овеяно тайной, поддающейся разгадке, как подсказывает название “Walkman”, в акте прогулки (здесь вспоминается горизонтальный модус восприятия города, о котором пишет де Серто в упомянутой нами ранее работе).

Таким образом, портативный плеер как аудиальный интерфейс, оперирующий на границе между приватным и публичным, служит, с одной стороны, овнешнению приватного, его демонстративному выставлению напоказ, а с другой, возникновению нового типа коллективной солидарности вокруг парадоксального сочетания общности практики и секретности ее конкретного содержания ${ }^{22}$. Кроме того, учитывая взаимную связь между музыкой и психологическим состоянием слушателя, сложно не увидеть в портативном музыкальном плеере своеобразный эквивалент «пульта управления» настроением, что удачно вписывается в логику театрализации внутренней жизни, характерной для данного интерфейса.

\section{Заключение}

Исходя из мысли о том, что дифференциация между приватной и публичной сферами является существенной частью городской жизни, мы попытались продемонстрировать продуктивность представления о границе между ними как о сложном медийном интерфейсе. Именно нечеткость границ ответственна, на наш взгляд, за создание эффекта материальности городской среды, понимаемой как способность оказывать сопротивление и повседневному действию, и аналитическому усилию со стороны индивида. Мы также выдвинули гипотезу о том, что, обратившись к аудиальной модальности, мы сможем - в силу особых ее свойств - более плодотворно описывать некоторые интерфейсы взаимодействия между публичным и приватным. Кроме того, мы попытались продемонстрировать теоретические построения, предложенные в работе, на примере двух медийных практик, получивших распространение в городах западного типа в XX в.

Хочется верить, что предложенная нами концептуальная рамка позволит поставить задачи и найти решения, выходящие за пределы предмета данной статьи. Так, многообещающими представляются исследования медийных эффектов материальности с привлечением данных ольфакторного, тактильного и проприоцептивного каналов восприятия ${ }^{23}$.

Благодаря различного рода интерфейсам между экстремумами абсолютной публичности и абсолютной приватности возникают промежуточные зоны: пространства, в которых приватное может стать предметом коллективного опыта и основой медийной солидарности нового типа. В духе зиммелевской социации (Vergesellschaftung) феномены приватного, публичного и городского в целом должны рассматриваться в качестве продуктов дискурсивного и медийного производства - непрерывного и изменчивого. И если шум заводов является признаком нормального течения промышленного производства, то шум и звуки города - это отголосок производства наполняющих его социальных связей, смыслов и ценностей.

22 Заметим, что ровно такая же логика применима к индивидуальному чтению «про себя» в общественных местах, - параллель, которую Хосокава упускает из вида. Чтение «про себя», появление которого Маклюэн связывает с распространением книгопечатания в Европе эпохи Возрождения, может также быть рассмотрено через призму изменения аудиального интерфейса взаимодействия между публичным и приватным - и заслуживает отдельного разговора.

23 В этих областях существует ряд фундаментальных работ, опирающихся на самые разнообразные теоретические основания. Мы отсылаем заинтересованного читателя к обзорным и библиографическим разделам следующих работ: [DeFazio, 2011; McQuire, 2008; Kang, 2007]. 


\section{Источники}

Барт Р. (1994) Эффект реальности // Барт Р. Избранные работы: Семиотика. Поэтика. С. 392-400.

Борхес Х.Л. (2017) Собрание сочинений: в 4-х т. Т. 1. Произведения 1942-1969 гг. СПб.: Амфора.

Де Серто М. (2008) По городу пешком // Социологическое обозрение. № 2. С. 24-38.

Деррида Ж. (1999) Голос и феномен // Деррида Ж. Голос и феномен и другие работы по теории знака Гуссерля. СПб.: Алетейя. С. 15-136.

Джекобс Дж. (2011) Смерть и жизнь больших американских городов. М.: Новое издательство.

Зиммель Г. (2002) Большие города и духовная жизнь // Логос. № 3 (34). С. 1-12.

Логутов А.В. (2014) Миры звукового воображения // Новое литературное обозрение. №6 (130).

Логутов A.B. (2016) Mowitt J. Sounds: the ambient humanities // Новое литературное обозрение. No. 138.

Маклюэн М. (2005) Галактика Гутенберга. Становление человека печатающего. М.: Академический Проект. Николаева Ю. (2014) Рынок радио в России. TNS.

Якобсон Р.О. (1987) О художественном реализме // Якобсон Р.О. Работы по поэтике. С. 387-393.

Carpenter E., McLuhan M. (1960) Acoustic space // Explorations in communication / E. Carpenter, M. McLuhan (eds). Boston: Beacon Press. P. 67.

Chion M. (1983) Guide des objetssonores / Préface de P. Schaeffer. Paris: Buchet / Chastel.

Clark N. (2000) "Botanizing on the asphalt"? The complex life of cosmopolitan bodies // Body and Society. No. 6. P. $12-33$.

DeFazio K. (2011) The city of the senses: urban culture and urban space. N.Y.: Palgrave Macmillan.

Habermas J. (1991) Strukturwandel der Öffentlichkeit. Untersuchungen zu einer Kategorie der bürgerlichen Gesellschaft. Frankfurt a. M.: Suhrkamp.

Hosokawa Sh. (1984) The Walkman effect // Popular music. No. 4. P. $165-180$
Hosokawa Sh. (2012) The Walkman effect // The sound studies reader / J. Sterne (ed.). N. Y.: Routledge. P. 167-183.

Johnson S. (2001) Emergence: the connected life of ants, brains, cities and software. L.: Allen Press.

Kang J. (2007) Urban sound environment. L., N.Y., Taylor $\&$ Francis.

Kornfeld A., Schiewe J., Dykes J. (2011) Audio cartography: Visual encoding of acoustic parameters // Advances in cartography and GIScience. Lecture notes in geoinformation and cartography. No. 1. P. 13-31. Amsterdam: Springer.

Labelle B. (2010) Acoustic territories: Sound culture and everyday life. N.Y., L.: Continuum.

Latham A., McCormack D.P. (2004) Moving cities: Rethinking the materialities of urban geographies // Progress in human geography. No. 28 (6). P. 701-724.

Massumi B. (2002) Parables for the virtual: movement, affect, sensation. L.: Duke University Press.

Matthews L. (2007) Hearing loss, tinnitus and mental health.A literature review. L.: The Royal National Institute for Deaf People.

McLuhan M. (1970) Culture is our business. N.Y.: McGrawHill.

McQuire S. (2008) The media city: Media, architecure and urban space. Los Angeles, L., New Delhi, Singapore: Sage Publications.

Mowitt J. (2015) Sounds: The ambient humanities. Oakland: University of California Press.

Resnick M. (1994) Turtles, termites and traffic jams: Explorations in massively parallel microworlds. Cambridge, MA; L.: MIT Press.

Schafer R.M. (1977) The soundscape: Our sonic environment and the tuning of the world. N.Y.: Knopf.

Southworth M. (1969) The sonic environment of cities // Environment and behavior. No. 1 (49). P. 49-70.

The Sound Studies Reader (2012) / J. Sterne (ed.). L.; N.Y.: Routledge. 


\title{
ANDREY LOGUTOV \\ SONIC PRACTICES AND THE MATERIALITY OF URBAN SPACE
}

\author{
Andrey Logutov, PhD, Associate Professor at the Department of Communication and Discourse Studies, \\ School of Philology, Moscow State University, head of Sound Anthropology Seminar (facebook.com/ \\ soundstudiesmoscow); 1 Leninskiye Gory, Moscow, 119991, Russian Federation. \\ E-mail: logutow@mail.ru
}

Abstract

This paper considers the urban sonic environment in terms of the distinction between the private and the public spheres. Based on ideas put forth by MacLuhan, Shaeffer, Mowitt and others, we suggest rethinking urban auditory practices as media interfaces operating at the borderline between the private and the public. The materiality of such interfaces contributes to the complexity of their theoretical description and mapping. According to one of the hypotheses advanced in the paper, some such issues may be resolved more efficiently if approached from an aural rather than a visual perspective. The point is exemplified by two practices of urban listening.

Keywords: sound studies; anthropology; urban sound; private; public

\section{References}

Barthes R. (1994) Effekt real'nosti [Effect of reality]. Barthes R. Izbrannie raboty. Semiotika. Poetika, pp. 392-400. (In Russian).

Borges J.L. (2017) Sobranie sochineniy: v 4 tomah. T. 1. Proizvedenija 1942-1969 gg. [Collected writings in 4 volumes. Vol. 1. Works of 1942-1969]. Saint Petersburg: Amfora. (In Russian)

Carpenter E., McLuhan M. (1960) Acoustic space. Explorations in communication / E. Carpenter, M. McLuhan (eds). Boston: Beacon Press, Pp. 67.

Chion M. (1983) Guide des objetssonores / Préface de P. Schaeffer. Paris: Buchet / Chastel.

Clark N. (2000) "Botanizing on the asphalt"? The complex life of cosmopolitan bodies. Body and Society, no 6, pp. 12-33.

De Certeau M. (2008) Po gorodu peshkom [Walking in the city]. Sociologicheskoe obozrenije, no 2, pp. 24-38. (In Russian)

DeFazio K. (2011) The city of the senses: urban culture and urban space. New York: Palgrave Macmillan.

Derrida J. (1999) Golos i fenomen [Voice and phenomenon]. Derrida J. Golos i fenomen i drugie raboty po teorii znaka Gusserla. Saint Petersburg: Aleteja. (In Russian)

Habermas J. (1991) Strukturwandel der Öffentlichkeit. Untersuchungenzueiner Kategorie der bürgerlichen Gesellschaft. Frankfurt a. M.: Suhrkamp.
Hosokawa Sh. (1984) The Walkman effect. Popular music, no 4, pp. 165-180.

Hosokawa Sh. (2012) The Walkman effect. The sound studies reader / J. Sterne (ed.). New York: Routledge, pp. 167-183.

Jacobs J. (2011) Smert' i zhizn' bol'shih amerikanskih gorodov [Life and death of great american cities]. Moscow: Novoe izdatel'stvo. (In Russian)

Jacobson R.O. (1987) O hudozhestvennom realizme [On realism in art]. Jacobson R.O. Raboty po poetike. Moscow, pp. 387-393. (In Russian)

Johnson S. (2001) Emergence: the connected life of ants, brains, cities and software. L.: Allen Press.

Kang J. (2007) Urban sound environment. L., N.Y., Taylor \& Francis.

Kornfeld A., Schiewe J., Dykes J. (2011) Audio cartography: Visual encoding of acoustic parameters. Advances in cartography and GIScience: Lecture notes in geoinformation and cartography. Amsterdam: Springer, no 1, pp. 13-31.

Labelle B. (2010) Acoustic territories: Sound culture and everyday life. N.Y., L.: Continuum.

Latham A., McCormack D.P. (2004) Moving cities: Rethinking the materialities of urban geographies. Progress in human geography, no 28 (6), pp. 701-724. 
Logutov A. (2014) Miry zvukovogo voobrazhenija [The worlds of sound imagination]. Novoe literaturnoe obozrenije, no (6) 130. (In Russian)

Logutov A. (2016) Mowitt J. Sounds: the ambient humanities. [Mowitt J. Sounds: the ambient humanities].Novoe literaturnoe obozrenije, no 138. (In Russian)

Massumi B. (2002) Parables for the virtual: movement, affect, sensation. L.: Duke University Press.

Matthews L. (2007) Hearing loss, tinnitus and mental health. A literature review. L.: The Royal National Institute for Deaf People.

McLuhan M. (1970) Culture is our business. N.Y.: McGrawHill.

McLuhan M. (2005) Galaktika Gutenberga. Stanovlenije cheloveka chitajuschego. [The Gutenberg Galaxy: The making of typographic man]. Moscow: Akademicheskij projekt. (In Russian)
McQuire S. (2008) The media city: Media, architecure and urban space. Los Angeles, L., New Delhi, Singapore: SAGE Publications.

Mowitt J. (2015) Sounds: The ambient humanities. Oakland: University of California Press.

Nikolaeva J. (2014) Rynok radio v Rossii [The radio market in Russia]. TNS. (In Russian)

Resnick M. Turtles, termites and traffic jams: Explorations in massively parallel microworlds. Cambridge, MA; L.: MIT Press, 1994.

Schafer R.M. (1977) The soundscape: Our sonic environment and the tuning of the world. N.Y.: Knopf.

Simmel G. (2002) Bol'shie goroda i duhovnaja zhizn' [The Metropolis and Mental life]. Logos, no 3 (34), pp. 1-12.

Southworth M. (1969) The sonic environment of cities. Environment and behavior, no 1 (49), pp. 49-70.

The Sound Studies Reader (2012) / J. Sterne (ed.). Routledge: L.; N.Y. 